\section{NATIONAL COLLEGE OF HOROLOGY AND INSTRUMENT TECHNOLOGY}

$\mathrm{T}$ HE National College of Horology and Instrument Technology was founded in 1947 for the training of technicians in the horological and instrument industries. It is accommodated within the Northampton Polytechnic, London, E.C.1. Shortly after the Second World War the horological manufacturing industry was re-established, and in consequence there was a great need for engineers with a good knowledge of horological theory and of production methods applicable to fine mechanisms. The first course instituted at the College was a three-year diploma course in horology for students over the age of sixteen. The standard of this diploma is of the order of the first part of a degree in engineering, and the curriculum, in addition to covering academic subjects, includes a liberal allocation of time to workshop technology and practice.

During recent years the academic content of the curriculum of the diploma course has been modified somewhat to include instrument technology as well as purely horological work, the remainder of the theoretical and almost the whole of the practical work of the course being found to be admirably suited to the needs of the instrument, as well as the horological, industry. In fact, many students leaving the College obtained posts in the field of instrument design, development and manufacture, even before these modifications were adopted.

The College' is equipped with a comprehensive range of general and specialized machine-tools and instruments suitable for almost any branch of fineinstrument and light-engineering production, and the variety of practical work given to students in this course is made as wide as possible. In addition to the specialized facilities in the National College itself, the full resources of the departments of the Polytechnic, including instrument engineering, mechanical and electrical engineering, applied physics, metallurgy and mathematics, are available for students at the College, these departments providing specialist lecturers in individual subjects.

Building extensions costing upwards of $£ 350,000$ are at present in hand at the Northampton Polytechnic, and the Instrument Engineering Department has acquired completely new workshops and laboratories. These extend its scope considerably and improve the facilities it is able to offer to the National College in connexion with advanced courses in instrument technology. Extensions to the premises of the National College are also planned which will more than double the space at present available. This space will be devoted to advanced workshops and laboratories for students in both horology and instrument technology.

To co-ordinate the diploma course in horology with training in industry, the British Clock and Watch Manufacturers' Association has sponsored a student-apprentice scheme which supplements the three years spent at the College with a further two years in the works of a member firm. Deferment from military service is normally granted for the full five years and, during the final two years, studentapprentices are expected to continue part-time for a Higher National Certificate. This enables them to qualify for graduateship of one of the engineering institutions-mechanical, electrical or production-partial exemption being granted on gaining the College diploma.

\section{Extension of Courses}

Although many ex-students are employed on instrument engineering with member firms of the British Clock and Watch Manufacturers' Association, the governors of the College are anxious to extend its facilities to other branches of the instrument industry. To this end, discussions have recently been held with the Scientific Instrument Manufacturers' Association to ascertain the types of courses best suited to the industry. An open day was held at the College on March 16 to enable member firms of the Association and other interested persons to inspect the workshops and laboratories, and this attracted some sixty to seventy representatives, many of whom expressed surprise and pleasure at the high quality and variety of equipment.

The two main courses proposed have received wide support. The first proposal is to establish a diploma course in instrument technology having much in common with the present diploma course in horology; with the development of this course, it may well be that horology will take its place as a special branch of instrument technology.

The second proposal is for an advanced course, one year in duration, for postgraduate and post-Higher National Certificate students. At present the instrument industry recruits to its technical and executive grades graduates in physics and engineering. It is found necessary to give these men a period of training in the industry before they are fully competent, and it is suggested that the College could undertake a good deal of this training. The actual length of this course would be one session, eight months in duration.

The curriculum will include a certain number of basic subjects such as applied physics, instrument design, workshop technology, metrology and industrial administration, as well as a number of optional subjects such as advanced mathematics, instrument workshop practice and metallurgy, together with particular branches of instrument theory such as mechanical, electrical, electronic, optical, industrial control and servo-mechanisms. It is envisaged that students holding degrees or Higher National Certificates in physics may well require tuition and practical experience in engineering, production and management subjects, as well as a more detailed knowledge of the technology with which their firm is associated. Students who have taken general engineering will need further tuition in applied physics, production and instrument engineering, while those who have National Certificates in production engineering may wish to study applied physics and perhaps some basic engineering subjects.

National colleges are intended to serve and co-operate fully with their respective industries, and it is therefore essential that approved forms of student-apprenticeships and postgraduate scholarships should be established by the trade associations or the larger firms.

\section{Production and Research}

Finally, it should be noted that the interests and facilities of the College are by no means limited to formal instruction. A certain amount of specialized 
manufacture is already undertaken where the work involved provides valuable experience for students, and the College is well equipped to accept suitably qualified students for research in various branches of design, development and production applicable to instruments, fine mechanisms, horology, automatic control and so on.

\section{UNIVERSITY COLLEGE OF THE WEST INDIES}

\section{DEPARTMENT OF ZOOLOGY \\ By Prof. N. MILLOTT}

T

HE West Indies have always formed a fruitful area for the prosecution of zoological research, and now, as in the past, excellent work is being done by the Institute of Jamaica and a well-established Natural History Society. In recent years the facilities for such studies have been increased by the establishment of a Department of Zoology in the new University College of the West Indies. Though facilities have been in existence from the inception of the College in 1948, it is only recently that they have been fully realized by the housing of the Department in permanent accommodation.

The Department is situated in the University grounds of some seven hundred acres and is readily accessible, being seven miles from Kingston. It is designed and organized for both teaching and research. As a teaching unit it is responsible for the training of undergraduates for degrees in science, and the intermediate and First M.B. examinations of the University of London, with which the College is privileged to maintain a special relationship. Provision has also been made for the training of postgraduate students for higher degrees.

The buildings were designed by the University College architects, Messrs. Norman and Dawbarn, of London, in conjunction with the head of the Department, and they were completed in October 1952.

Mostly on one level, the laboratories include a large elementary and a smaller advanced teaching laboratory, suitable for the study of systematic zoology, animal morphology, histology, etc. In addition, there are an experimental laboratory for physiological studies, a small museum, an aquarium room, offices, a photographic dark room and a lecture room. Two research laboratories are provided. All the laboratories are fitted with the usual services, and in addition, both the experimental laboratory and the aquarium room have compressed-air mains. Very shortly a salt-water circulator will be installed in the aquarium room. The furnishings are executed in local woods and were designed and constructed on the University College site.

The laboratories have been equipped and staffed, so far as possible, for a comprehensive study of zoology, rather than for highly specialized studies of particular aspects. In this way it is hoped that the Department will not only be able to give its students an adequate training in the ever-widening sphere of zoology, but will also provide a type of research centre that has long been required in the central Caribbean.

From the first the Department has aimed at encouraging visiting research workers to use its laboratories and in this a real beginning has been made, the Department having already accommodated research workers under the Fulbright scheme and two members of the staff of the University of Glasgow. It is hoped that other institutions and organizations will encourage investigators to use the facilities now available.

Since the beginning, members of the teaching staff of the Department have been actively engaged in research, and the existing programme falls into six main divisions. A study of the Collembola of Jamaican soils is being undertaken, which, initially, will involve the determination of species, and later, studies of population density and distribution. The Nuffield Foundation has generously offered financial assistance for this study. A second division consists of evolutionary studies on snakes and lizards. These have involved investigations of the details of speciation in Jamaican reptiles, comparative anatomical studies including a special study of the retina, and distributional studies which bear on the evolution of higher taxonomic categories and the problem of the origin of snakes. Researches on the thymus of

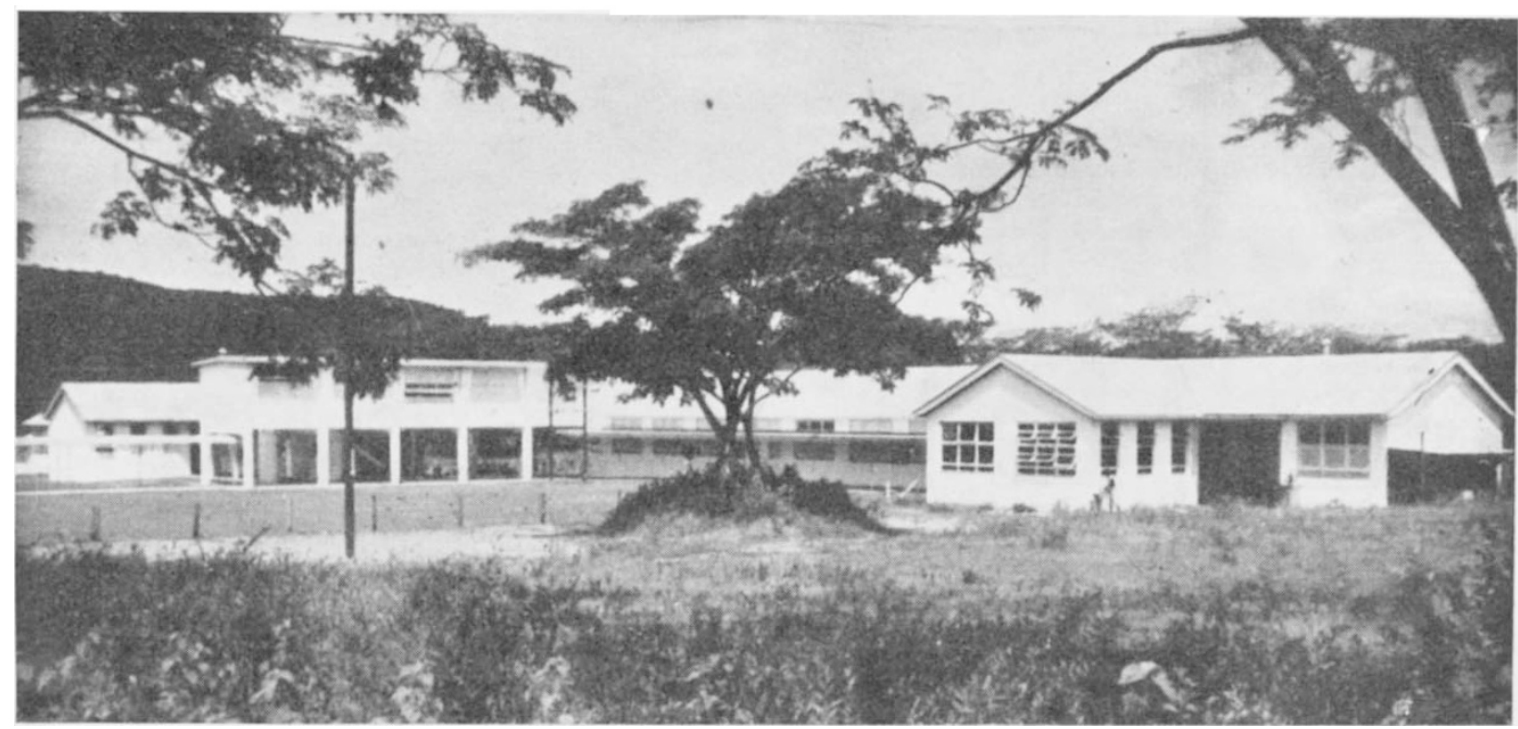

Zoology Laboratories University College of the West Indies 